\title{
Affect and Effect in Interdisciplinary Research Collaboration
}

\author{
Line Hillersdal \\ Department of Anthropology, University of Copenhagen, Denmark/ \\ line.hillersdal@anthro.ku.dk \\ Astrid P. Jespersen \\ Copenhagen Center for Health Research in the Humanities, University of Copenhagen, Denmark \\ Bjarke Oxlund \\ Department of Anthropology, University of Copenhagen, Denmark
}

Birgitte Bruun

Department of Anthropology, University of Copenhagen, Denmark

\begin{abstract}
Research across disciplines is described as beset with problems of epistemological hierarchies and incommensurable categories. Having worked in two large interdisciplinary research projects on obesity and cholesterol lowering medicine in Denmark, we recognize such tensions. We explore the practice and outcome of interdisciplinary research, however, with a starting point in a different kind of tension that is affective. Based on analysis of four interdisciplinary situations, we suggest that embodied experiences of amusement, boredom or doubt are signposts of both differences and connections between people and concerns. Drawing on Haraway's (1997) notion of 'response-ability' and Verran's (2001) concept of 'generative critique' we propose that attention to affective tensions can be generative of effects not only on modes of collaboration, but also on the knowledge we contribute, and the ways we engage the world as researchers. The article contributes to ongoing discussions within science and technology studies, about affect in scientific knowledge production.
\end{abstract}

Keywords: interdisciplinarity, affect, response-able, cholesterol, obesity, Denmark

\section{Introduction}

Interdisciplinary research is high on the political agenda in Denmark and internationally. Large funding schemes that finance interdisciplinary projects have proliferated since the 1990s[1] because interdisciplinarity is increasingly seen as necessary for tackling today's major societal challenges. Interdisciplinarity has even been coined "the natural crisis response" (Strathern, 2004). This shift towards interdisciplinarity has happened simultaneously with a change in the way 
research is funded and evaluated. Today, a greater proportion of funding goes to earmarked purposes, and to new ways of evaluating research that focus more on societal benefits and (financial) accountability than was previously the case (Gibbons, 1994; Strathern, 2004). Whereas both Gibbons and colleagues (1994) and Nowotny and colleagues (2001) have characterized this development as a move from basic research to problemdriven research, others, e.g. Jasanoff (2004), have described the same agenda as politically enforced emphasizing the mixing of politics and science in these research grants.

These changes have led to a practice of research collaboration in which knowledge production has brought new and more institutions and disciplines together. New research fields, such as synthetic biology, social neurobiology, epigenetics, and many more, engage disciplines in new ways and challenge previous classifications and disciplinary taxonomies (Pedersen et al., 2015). The trend not only implies that some scientific issues and societal challenges, such as obesity or cholesterol treatment, are considered a matter of biological and social entanglement (Rose, 2013; Meloni, 2014). It also calls upon the social sciences and humanities in a general turn to culture as a source of explanations and solutions (Suchman, 2013; Jespersen et al. 2012; Elgaard Jensen 2012). In interdisciplinary research programs, the social sciences and humanities are often considered able to handle so called "complex problems" and "human factors" (e.g. University of Copenhagen, 2012), which emphasize the need for expertise in how culture, sociality and values play a role in such complex problems.

The university-funded interdisciplinary research projects that we report from were part of this general political push for interdisciplinary collaboration. In 2013, the University of Copenhagen launched the "Excellence Programme for Interdisciplinary Research" and awarded 18 interdisciplinary research projects spanning all faculties a total amount of $€ 66 \mathrm{~m}$. The projects that received funding involved topics such as climate change, big data, genetic engineering and ageing, as well as obesity, and high levels of cholesterol in the blood, which were the two themes we became involved in. In the development of our argument here, we draw upon our experience as relatively new collaborators in this kind of interdisciplinary research.

We were aware of the many examples of how social scientists experience being recruited into interdisciplinary research projects without having their knowledge and experience acknowledged on their own terms (Rabinow and Bennett, 2012; Callard and Fitzgerald, 2015). This can lead to a sense of putting one's professional integrity and ambition at stake (Prainsack et al., 2010) or to difficulties in collaboration because of a historically rooted hierarchy between the natural and the social sciences (Albert et al., 2009). Historically, research collaboration has been fraught with questions of epistemological difference and disciplinary hierarchies, which have often afforded the qualitative, humanistic side a secondary position (see, for example, Albert et al., 2008; Prainsack et al., 2010). In the 1990s, the 'ELSI model' emerged as particular formalisation of interdisciplinary collaboration between the natural and the social sciences and humanities, in which the latter two were assigned the tasks of addressing the Ethical, Legal and Social Implications of any given problem (Strathern, 2004). The ELSI model thus entails certain expectations of how the social sciences can contribute, and of how this knowledge may be relevant as an addendum to problems defined by natural sciences (Rip, 2009).

There are indeed political and epistemological issues in taking up an interdisciplinary approach. Similarly, there are structural explanations for why involvement in interdisciplinarity means that researchers must navigate very different standards, obligations and requirements for their research. At the same time, interdisciplinarity has become an indisputable and important contemporary context for scientific knowledge production. We welcome this movement towards engaging the world together with other disciplines, but are wary of celebrating interdisciplinarity as a path that will automatically lead to innovation or better solutions to societal problems. Instead, we consider what happens to what we think of as our disciplinary expertise, and to our research objects, when we collaborate with other disciplines on an already named societal problem. We have paid attention to what happens 
in practice, in the actual doing of interdisciplinary research projects, and to what comes out of collaboration in practice.

Instead of dwelling on incommensurabilities between disciplines in collaboration, we explore disciplinary differences by addressing the affective tensions that develop in these collaborations. We unfold the kinds of affective tensions that arise in concrete situations where we are not able to follow the arguments and interests of others, and where we begin to share doubts about how to approach the problems that we try to address together with other scientists or the public. Our contribution to debates about how post-ELSI interdisciplinary collaboration might work (Balmer et al., 2016) is to explore the effects of keeping open to unruly emotions as suggested by Jerak-Zuiderent (2014) and to explore what differences that such affective tensions might point to. We propose to regard the excitement, awkwardness or bewilderment of travelling new territories as starting points, which are not only interesting in themselves as more or less tacit effects (Fitzgerald et al., 2014), but also as important catalysts for cultivating attention and sensitivity to meaningful differences (Haraway, 1997). Sensitivity to differences may be prompted by scholarly disagreements that are made legitimate by the conventions of intellectual arguments, but these tensions may also make themselves known in less verbalised ways. In our experience, difference is indeed often first felt or experienced as an affective tension in particular situations, as excitement, bewilderment, doubt, resignation, etc., rather than as an explicated, verbalised understanding. Sensitivity to (disciplinary) differences may lead to other ways of addressing a research object and ultimately a societal problem that do not simply reproduce a focus on barriers between disciplines. The article thus contributes to ongoing discussions within science and technology studies inspired by the strand of research that has centered on emotions and affects in the practices of science.

By analysing four situations of interdisciplinary collaboration, we will show how affective tensions carry the potential to become generative of effects on both interdisciplinary research processes and their outcomes. The questions we explore in this article are: How can attention to affect open new avenues of enquiry and pathways for the practice of interdisciplinarity? How can we acknowledge what affect does and what it means for the ways that we engage the world through interdisciplinary collaboration?

Sensitivity to difference, as when sharing doubts with projects colleagues about how to approach a research problem, is a promising starting point for pursuing a generative critique (Verran, 2001). A generative critique, we shall propose, opens for effects of interdisciplinarity that are quite different from the visions of 'robust' solutions demanded and proposed by common discourses about interdisciplinarity in late-modern knowledge societies.

\section{Our positions in the Governing Obesity [2] and Lifestat projects [3]}

A large part of the literature dealing specifically with interdisciplinarity is aimed at identifying and categorizing forms of interdisciplinarity through taxonomies and levels of integration between disciplines (Klein, 2010; Repko and Szostak, 2017; Frodeman et al., 2010; Zierhofer and Burger, 2007) [4]. The concept of interdisciplinarity in our projects, however, was not settled upon beforehand or easily defined (cf. Moran, 2010; Barry and Born, 2013). As a consequence of the political drive towards finding solutions through interdisciplinary collaboration, and the funding criteria that follow from this development, there can be a risk that interdisciplinary research teams are formed on the basis of intentions rather than on collective reflections about how to organise and practice interdisciplinarity. In the beginning of our projects, interdisciplinarity as a framework and topic figured mostly at a strategic level and in external presentations. Internally in the projects, the way forward was more diffuse. In practice, we began working with our colleagues from other disciplines without any clear definition or road map of interdisciplinary collaboration (cf. Lindvig and Hillersdal). Thus, we took part in making interdisciplinarity from scratch and in what follows we explore the pragmatics and situated concern of our own practices and collaborations.

The two interdisciplinary collaborations that we were part of demonstrated an asymmetry 
between the disciplines involved, both in terms of the distribution of financial resources, and in terms of the general inclination to prioritize a natural scientific understanding of evidence. While this was obvious for all from the beginning of the projects, it did not determine forms of collaboration and their outcomes, as we will demonstrate below. With regard to our own role in defining the projects, we were all involved at different levels in the planning and development of the two large projects, and we share responsibility for the ways that collaboration developed in practice. Here, we briefly present the two interdisciplinary research projects that we were engaged in, and explain how we came to write this article.

Two of the authors (Hillersdal), and (Jespersen) were based in a center for health research in the humanities, and involved in the Governing Obesity (GO) project, which was a large interdisciplinary project that sought new ways to understand, prevent and treat the 'problem of obesity'. The basic premise of the project was that obesity is a problem, and that the prevalence of obesity is increasing in most parts of the world[5]. The project was structured around five interdisciplinary work packages, each comprising a crossfaculty team of researchers from the University of Copenhagen. Each of these work packages examined different aspects of the problem of obesity; defining the causes of childhood obesity, optimization of prevention strategies, success criteria for surgical treatment of obesity, government regulation, and obesity in interdisciplinary research. Hillersdal's role was to investigate how interdisciplinarity was enacted in practice, and how 'the problem of obesity' co-configured in specific collaborations. She had been involved in the development of the project design, and worked with many of the involved researchers in an earlier project on obesity surgery (Hillersdal et al., 2015, 2016). Jespersen was part of the steering committee of $\mathrm{GO}$ and involved in two of the work packages as a PI of the work package focusing on interdisciplinary work practices and co-PI in a work package centered around a clinical trial investigating the health effects on physical activity (Larsen et al., 2017).

The two other authors of this article (Oxlund) and (Bruun) were part of the interdisciplinary project "Living with statins - LIFESTAT" and based at the department of Anthropology at the University of Copenhagen. LIFESTAT's main objective was to study various effects of cholesterol-lowering drugs. The problem that framed the project was that every sixth, otherwise heart-healthy, Danes over the age of 50 take cholesterol-lowering drugs daily to prevent the onset of cardiovascular disease. Internationally, there is disagreement among specialists about the evidence to justify mass treatment of healthy people, who may experience side effects, such as muscle soreness, from the treatment. Given this disagreement, the LIFESTAT project examined the effects of cholesterol-lowering drugs in people's bodies, the social effects of the polarized media coverage on cholesterol-lowering drugs, and the societal impact of the practice of treating statistical risk with medicine. Project funds and employees were split between the Department of Anthropology, the Department of Media and Communication, and between three departments at the Faculty of Medicine. Oxlund was part of the original team of researchers who drafted the LIFESTAT project and became co-PI in charge of the anthropological component of the overall interdisciplinary undertaking (Christensen et al., 2016). Initially, Bruun's role in the project was to study research participants' experiences of laboratory tests at the Department of Biomedical Sciences. These tests included a measure of muscle soreness that appeared quite one-dimensional, so the author proposed to supplement the measure with other methods. In this way, the author became involved in research at the lab and in interdisciplinary collaboration in practice.

Early on in both our projects, the authors met at a social event, shared field work stories and immediately recognized each other's observations. We then began to meet regularly across the two projects to share detailed accounts of particular fieldwork situations and the roles we could shift between in the collaboration (cf. Balmer et al., 2015; Morris and Hebden, 2008). In the beginning, we reflected upon the challenges and the confusion, and the awkwardness and silences that accompanied them; but our attention to the affective tensions of collaboration gradually became more analytical, and we 
tried to explore them as primary openings for insights into the everyday experience of interdisciplinary collaboration; and into how we collaborated with other disciplines. In the same move, our attention switched from our own roles in collaboration to what happened to our research objects in collaboration. Soon, the idea to work through our observations in writing across the two projects emerged. Our analyses build on empirical material collected via ethnographic methods across the two projects (Hammersley and Atkinson, 1995; Marcus, 1995). In this article, we draw on interviews and focus group interviews with our interlocutors. We include field notes from participatory observations as well as notes from our personal research logs[6]. In addition to this, we draw on analyses of documents, and written communication from the research projects. Based on our individual fieldwork and our continuous shared reflections this article is one attempt to work through the connections between affect and knowledge production in collaboration across disciplines.

The results and insights of these collaborations were presented at seminars and annual meetings in both projects. Part of the ambition with these meetings was to contribute to the overall research aim of the projects and to share ongoing analyses from all the subprojects, which was a commitment from all project partners from the beginning of the research. However, despite good intentions as we shall show - working with and extending on the findings from colleagues was not so straightforward and the intended results not so easily produced. Not that collaboration was not productive - it was indeed - but in a different and more subtle way than project applications promised.

\section{Affect and effect of collaboration}

To date only few studies of the mundane experience of interdisciplinarity and its effects on collaboration and outcomes of research have been published (Barry and Born, 2013; Callard and Fitzgerald, 2015). Callard and Fitzgerald (2015) reflect on how the interdisciplinary research projects they were part of were both messy and confusing. They emphasize the importance of emotions in collaboration and describe how their own ambivalent feelings of reservation and criticism are part of, and even enhance interdisciplinary cooperation. They propose an ambiguous ethics, to convey how they, as project collaborators, developed an awareness of what is inconvenient, and that which is best left unsaid in cooperation. Their description of a way to be - and remain - in interdisciplinary projects involved a situated habitus of dealing with ambivalence which has been inspirational for our understanding of the projects we were part of (Callard and Fitzgerald, 2015). Attention to connections between emotion and knowledge adds to the growing body of studies of the role of affect in scientific knowledge production.

We find that attention to affect opens up a salient theoretical space to consider the practices of scientific knowledge-making. We draw from a particular branch of this literature, which describes scientific knowledge making as a "choreography of affect" (Kerr and Garforth, 2016). These studies analyse researchers' embodiment, care and interaction with their intellectual projects as 'affective practices' through which routines of scientific knowledge-making is accomplished (Myers, 2008, 2006; Parker and Hackett, 2012; Jespersen et al., 2013). However, our focus is on the often spontaneous affective tensions we experienced that arose in collaborative situations and negotiational arenas involving different norms and paradigms of knowledge production. Hence, we are not primarily preoccupied with emotions as they are experienced by individuals, but rather with affect as "forces of encounters" among all kinds of human and nonhuman bodies (Gregg and Seigworth, 2010: 2). This distinction between emotion and affect is drawn from affect studies that conceptualise affect as relational and not belonging to particular individuals or representing private emotions. Instead, affect is understood as the effects of situated practices of social bodies (Bennett, 2009; Blackman and Venn, 2010; Seyfert, 2012; Gregg and Seigworth, 2010).

We contribute to current discussions about the affective turn in science studies by exploring affect in knowledge production as generative of new avenues for inquiry. We are inspired by Verran's (1999) example from a Nigerian classroom on sharing differences in approach to the scientific 
practice of quantifying. Verran analyses her own and her interlocutors' spontaneous laughter as key. She makes us aware of how we immediately experience bodily responses when we meet and experience different ways of enacting the world, hence: "The sort of laughter that grows from seeing a certainty disrupted to become a different sort of certainty: a certainty that sees itself" (Verran, 1999: 141). By pointing to this situated reflexivity of an affective tension, she reminds us of the way affect may direct us to otherwise overlooked differences that have a disturbing effect or lead to a sense of "disconcertment." Verran's (1999) point is that this fleeting sense of disconcertment may open new avenues for understanding. As she states: "Keeping the disconcertment is important, it alerts us that here is an occasion for telling stories, which might generate new possibilities for answering moral questions of how to live" (Verran, 1999: 136).

Moving one step further from noticing difference through the experience of embodied affect to exploring this experience of difference more thoroughly, we draw on Haraway's (1997: 71) concept of 'response-ability'. Response-ability denotes the capability to work with sensitivity to difference. The concept covers how, in a collaboration, the ability to act in relation to the other's interests, which one does not necessarily share, requires a particular kind of sensitivity. Applied to our observations, the concept allows us to nuance our understanding of what happens when researchers from different disciplines try to bring together their different perspectives on a given problem.

We find this sensitivity to difference implicated in moments of collaboration when e.g. the solving of a problem becomes an unsettled question to all parties and thus opens a potentially inclusive/ democratic space for the reconfiguration of that problem, and thereby for the production of new knowledge and approaches to solutions. Finally, we draw on Verran's (2001: 20) term 'generative critique' to suggest affective tensions in collaborative work as a possible entry point for imagining new ways to engage the world. Generative critique does not offer alternative solutions to problems, but the concept points to an ability to develop other ways of 'seeing and doing' problems. In our analysis, we want to reconsider and revalue what we find to be effects of engaging in interdisciplinary collaboration. We want to expand the notion of effect to not only cover an already defined outcome, but also the ability to recognize the many subtle and constantly emerging differences and connections between concerns and researchers (as they make themselves known through affective tensions).

In the following sections, we present four situations, two from each of our two research projects. All four situations describe interdisciplinary meetings and negotiations and what came out of them. In the first two examples, we focus on the way affect plays a role in interdisciplinary exploration of problems, and the next two situations demonstrate how affect have effects by reconfiguring what we find to be the actual products or promises of interdisciplinary research collaboration.

\section{Affect as markers of differences in interdisciplinary collaboration}

The first situation we describe shows a process in which the author and her colleagues in the LIFESTAT project grapple with different ideas about how to describe muscle soreness. Whereas this first situation concerns spontaneous negotiations and the affect that emerged with them, the subsequent situation from $\mathrm{GO}$ project shows the deliberate exploration of difference in terms of multiple, concurrent or coexisting analyses of an object - in this case a meal.

\section{Soreness logbook in the LIFESTAT project on cholesterol-lowering medication}

One commonly reported side effect of cholesterol-lowering drugs is varying degrees of muscle soreness and discomfort. One hypothesis is that the coenzyme Q10 can counteract the muscle soreness, and this was tested in the LIFESTAT project by following a number of study participants who take a supplement of Q10 or placebo for eight weeks. Various physical examinations were conducted before and after the eight weeks, and subjects were also asked to mark on a continuum scale how intensely they experienced any muscle discomfort before and after the eight weeks of 
treatment. This continuum scale, the VAS instrument (Visual Analogue Scale), is based on a onedimensional conception of pain as a matter of intensity located within an individual body.

"Many anthropologists see pain as relational," Bruun remarked to one of the researchers from the wet side of the LIFESTAT project. "We observe how the experience of pain is formed in relation to others". The researchers sat in a group during the first joint seminar in the project. The discussion partner's attention to what she had said seemed unchanged, but his silence, and the way he leaned back in his chair, pulled in his chin and raised his eyebrows while still looking at her also testified to something else. Then a break in the group work interrupted the conversation, and she did not manage to follow up on the quite "disconcerting" moment when it became apparent for the researchers how different their views of pain actually were. Still, this moment spurred the idea of developing a logbook for study participants to register muscle soreness, discomfort and pain that could take account of pain in more than one way.

The researchers from "the wet side" of the project were not entirely satisfied with the VAS score that they used. Many of them perceived the instrument as a rather inaccurate measure, because what one person would rate a "two" on the scale, another person might rate a "three", so using it as they did as a summative measure was flawed. However, there was no better alternative, and they hoped that including qualitative data might "offer something" as they said. Together, the researchers developed a logbook for study participants to fill in. The idea was to expand on the amount and type of data representing muscle pain and soreness in the context of daily life and participation in the LIFESTAT project.

Several versions of the logbook were developed before the human physiologists; the doctors and the anthropologist were satisfied with the result. The final version was divided into four sections - one for each day to be recorded. Each section began with a VAS score, followed by a space to indicate what kinds of physical activity they had carried out on that particular day, and with what intensity. This space was intended to test a hypothesis about the relationship between physical activity and intensity of muscle discom- fort. Furthermore, the logbook contained a blank page for the participants to describe his or her muscle pains and well-being during their day. Finally, each logbook was followed up by an interview with each of the study participants in their homes, based on their entries in the logbook. The logbook enabled very different representations of muscle soreness as measurable, localized and comparable; as a result of physical activity; as something that was related to their wider sense of well-being on the recorded day; and as communicated to Bruun in the subsequent interview.

During the joint development of the logbook differences between the researchers' ways of thinking about the body and of participants' knowledge of soreness became apparent. In an earlier version Bruun's suggestion to use a picture of a walking croquis doll for the study participants to mark where they were sore was challenged by the biochemists in the team, and instead two drawings of a human body, one from the front and the other from the back, were proposed. Each of the large muscle groups on the drawings had a number that participants should refer to in the logbook.

At this stage in the process, differences between the researchers' views of bodies and what images they thought would resonate best with study participants were first expressed in the anthropologist teasing the biomedical researchers with their image of bodies as machines, whereas Bruun at some point was accused of applying aurareading as her main method. These jokes worked to delineate disciplinary territories and to hold up stereotypes at the same time as they blurred and softened them by making us laugh at ourselves and each other. Here, it is relevant to note that the joking took place between researchers occupying fairly equal positions in terms of rank, and at a time when the group of researchers had spent a considerable amount of time together already, which greatly influenced the way this joking worked. Joking was an affective expression of both unease with difference and a readiness to explore it. The joking then turned into more concrete negotiations based on explications of rationalities. For example, the replacement of the image of a three-dimensional body in movement with a flat, enumerated and divided body was agreed on 
because aesthetic appeal was given less weight than some researchers' need to identify and count exactly which muscle areas in the body the participants identified as sore.

The researchers agreed to gather data through the logbook, although its final form was not seen as ideal from any mono-disciplinary point of view. Although the logbook led to a significant increase in the number of VAS measurements for each participant in the study, the degree of statistical power was still relatively low. In fact, the increase in measurements may have made the limitations of the VAS as a tool even more apparent. One team member from the lab found this uncertainty unacceptable, so an extra meeting was called for in the team to address doubts and to re-confirm everybody's commitment to applying the log-book in spite of its shortcomings.

The logbook can be seen as a boundary object, which is indistinct enough to be used for quite different purposes by different parties, but robust enough to be recognized as the same object across the sites where it is activated (Star and Griesemer, 1989). Boundary objects may emerge when social worlds that are based on potentially conflicting concepts work together. The point here is not to describe the logbook as a boundary object. Rather it is to show how affects (scepticism, unease, laughter, a sense of sharing risk) worked in, and sometimes catalysed, the conception, development and use of the logbook in an interdisciplinary team that was able to explicate and negotiate different connections to body, soreness, quantity and quality, and make them materialize into the logbook. In other words, the key point here is that members of diverse social worlds were aware of their mutual diversity and came to work explicitly with it.

The process in which the logbook was developed elicited various explications of what muscle soreness is and how it can best be captured. Thereby, a space for negotiation was created where the object, i.e., soreness, was discussed and studied in its multiple meanings. With all these conditions and reservations, the logbook became regarded as a shared and exploratory methodological experiment, in which all project participants were willing to make connections between their own and other disciplines' ideas about body and soreness. The process of making these connections across differences, making the researchers doubt their own ideas of how to capture pain, is perhaps just as important a contribution to the project as the results of analysing the study participants' entries in the logbooks.

\section{Researchers' dialogue on the appetite day in the $G O$ project on obesity}

A nutritional physiologist and Hillersdal had been project colleagues for more than a year. He was interested in how appetite is influenced by physical exercise. The goal of his research was to be able to recommend how much we should exercise for optimal appetite regulation. Hillersdal conducted field work during meal tests in the test lab and followed volunteers and staff during test days to investigate what eating in the laboratory is.

In order to explore their different approaches to appetite as a research object, she initiated a dialogic experiment[7] with a focus on knowledge production and analysis as co-creation (Hastrup, 2014). The dialogic experiment focused on three shared issues: What is appetite for us? How do we investigate appetite? And why do we study appetite? The researchers shared an interest in finding ways to describe their knowledge of appetite, eating, hunger and satiety that might convey their different perspectives and interpretations to each other.

The dialogic experiment took up examples from visits to the Lab. The first topic that the researchers discussed was the morning meal prepared for the test participants. Hillersdal had noticed that her colleague clipped off the top of the bun he served to a research participant with a pair of scissors. The reason was that today's trial participant was a woman, and women, according to nutritional science, need fewer calories than men. This spurred a discussion on how a standardised test meal is already gendered. The study participant, who had arrived for the test day was a woman in her thirties, a mother of two children aged three and seven years. She spoke with a slight accent, and told them that she worked in accounting. She had been about to drop out of the study, but after massive encouragement from the researchers, she came back to finish the last day of testing in the 
laboratory. "It's appetite day and she is not interested in this test, because she does not like the test meal. She does not eat pasta with meat sauce, which is what the standardized test meal is", he explained. The test participant herself suggested rice and curry. This was not possible and for good reasons. The meal served in the lab was as "a constant", which made it possible to compare the results with those of other similar studies around the world.

In the lab, participants would lie in a hospital bed for a full day. The room was packed with equipment, a giant treadmill, and polystyrene boxes, which led to a discussion about what influences appetite and the context of appetite. Hillersdal and the nutritional physiologist talked about eating and meals as something fundamentally social, and linked to identity and communities; to everyday life in a family; or to the role of the provider. They talked about how eating in the lab was an unfamiliar experience and how that might affect the test person's appetite. On the one hand, appetite was a contextual 'confounder' in an experimental setting, which at the same time made it hard to relate to everyday lives and family meals. Imagining the lab as a living room with draped curtains and flowerpots in the windows was one metaphor they explored together jokingly. They could both agree that eating was social, but it was not an aspect he, in the role as a nutritional physiologist, could include in his analysis, though the interaction in the daily work of test-takers demanded that he took the social and cultural significance of the food into account.

The aim of the dialogic experiment was to find ways to talk about appetite by unfolding what appetite might be in their different perspectives and methodologies, which at the same time allowed their understandings to coexist. In the process, they became able to analyse appetite together by making comparisons to a new shared object, which emerged from the conversation. During their talk, they often felt like going in circles, and it was hard for them to express what might be a valid connection between their perspectives on appetite. Hillersdal's first impulse was to recognize when her colleague talked about appetite as, e.g., an expression of a hormone response, but the challenge was to link his particular version of appetite to her analysis of appetite as embedded in a social context. Staying with the affective tensions of circling around a shared object exploring associations and concepts made them both confused in terms of the implicit closure of analysis that they found themselves searching for. The outcome of the talk was a realisation that they shared a complex understanding of appetite, but it was the dialogic experiment that made this visible through the affective tensions that unfolded diverse concepts and experiences in a conversation, which they both were able to connect to. The process itself became the shared object in a joint analysis of an ambiguous object.

The two cases above describe meetings between disciplines regarding two objects or problems, muscle soreness and appetite, respectively. Whereas we, as scholars, are well aware of ambiguities in our research objects (which may be dealt with by defining them away, or by making them a point in themselves, etc.), we experienced this ambiguity anew and most poignantly through affect-laden exchanges with others. Instead of withdrawing from the complexity brought on by meeting other disciplines' ways of capturing our shared problem, we explicitly explored the connections between the elements that formed our objects together.

The logbook of muscle soreness raised questions about how to capture soreness; muscle soreness was allowed to remain suspended between being quantifiable and not, neither one nor the other. The logbook collation of qualitative and quantitative approaches to muscle soreness meant that habitual categories were open for new interpretations. This opened for doubts and in this case a willingness to share doubts about what muscle soreness really is and for jokes about how to capture it, and ultimately know it.

The appetite conversation was an attempt to share each others' analyses in an explicit way using the affective tensions arising from experiencing and sharing difference. Acknowledging disconcerting differences from the start of the conversation - and taking them as a basis for the conversation - the researchers shared a curiosity for appetite and a search for connections between the very different elements that formed their object of research. In this way the appetite 
conversation shows the same joint analysis as the one that emerged in the work with the soreness logbook, although it was constructed as a much more deliberate reflexive experiment. In this sense, our analysis draws out how affect in negotiating collaboration can do "ontological work" (Marres, 2009), by creating connections between otherwise separate categories.

Connections between disciplines, people and concerns experienced as affect challenge our perceptions of what we are investigating. The on-going conceptualisation of appetite and soreness in the projects continuously shifted and displaced our objects. In practice, delineated disciplinary fields and asymmetries gave way to a fluid movement between views on the object, so that we, at times were able to engage in several analyses simultaneously. Haraway describes our ability to recognize differences between our own and other people's knowledge about a field, as a capacity for being 'response-able' (Haraway, 1997: 71). When we spend time with others whom we want to understand, we also gain a better sense of their interests and their arguments, which offers a different position or starting point for analysis of what the problem is, and what questions it raises.

In the following, we analyse two further situations. We examine two meetings in the projects, and study how affective tensions in them can point to new and emerging connections. We show how affective moments may point to other ways of framing questions and seeing a shared object of research, which thereby carry the potential for effects in terms of engaging with the world with new knowledge.

\section{Affect as entry point to explore connections in interdisciplinary collaboration}

\section{The "free choice" debate in the project}

All work packages in the $\mathrm{GO}$ project met twice a year. At one of the annual meetings colleges from the Department of Philosophy were responsible for a shared session, and they introduced a discussion of whether or not people have a free will with respect to responsibility of one's own health. The core of the issue they raised referred to the way health has become a goal in itself (Lupton, 1995).
The question they wanted us to respond to was whether people have the freedom to decide for themselves, and thus if they can exercise a right not to be driven by contemporary norms about health and how to perform their body, and basically live as they like.

A researcher from one of the other work packages was discussion partner to the philosopher's presentation, but instead of commenting on the presentation, he said in a lighthearted and humorous tone that now he would settle for the facts, namely, how little exercise it takes to become healthy. After his presentation of the health effects of different intensities of exercise, the stage was set for a joint discussion.

Subsequently, there was general silence in the whole assembly. An invited professor from Canada researching the correlation between obesity and physical activity was visibly provoked by the question posed by the philosophers, and saw it as a mistake not to help people with obesity. Should we as scientists just leave people to their own behaviour? It developed into a discussion about the right to choose one's own lifestyle in a society with a strong focus on health versus a society with a lack of regulation and social security. Could we, researchers dealing with Danish subjects, in other words allow ourselves to insist on the existence of a choice because Denmark is a welfare state? A social science researcher, also provoked, asked whether they, the subjects of the scholarly discussions, were someone anybody had met and implied that many assumptions were made on behalf of "the fat" or the not-so-health-motivated.

From then on, no one really picked up the invitation to debate. Many in the large group let their attention stray and started checking mails. Others looked to the floor, or out of the windows, it seemed, to avoid eye contact with the conveners. This had happened before, so it was not just a matter of discussions being initiated by a philosopher. But why did arguments not materialize and why was the meeting saturated with a sense of lack of commitment, even boredom? One reason might be that the premise of the debate was unclear or the question too broad. What was interesting at the meeting was how the common problem, namely the individual responsibility for health, emerged as something 
that no experts could ultimately define nor help achieve. Everyone could, in some way, offer their own version, or interpretation, and thus it was difficult to be called upon as an expert. The philosophers raised a critique of the idea of the free choice that was naturalized for them, but in the response and discussion that arose no one could be experts. At first everyone spoke from professional positions, but in the particular context, all of these statements also at once assimilated, and thus it was difficult to establish direction, and to select or define the problem. This resulted in a tense atmosphere, a disconcerting moment, but instead of interpreting it as an expression of something unresolved, it conveyed a shared experience of a problem in terms of indignation from both the Canadian intervention researcher and from the social scientist, leading to frustration and discomfort in the whole group about who we were talking about, what should be done and in relation to whom.

The immediate result of the discussion was the realization that raising the question of personal responsibility for one's own health did not by itself point to a self-evident problem or a well-defined solution. It revealed what is often hidden, namely the fact that health is never neutral or just a technical standard to be worked on. The tensions represented health as negotiation of moral and human values, rather than as established facts, which raised the question of who had called upon us as experts to act on anyone's behalf in the first place.

\section{Participants' meeting in the LIFESTAT project}

At some point in the LIFESTAT project, the idea of a meeting for study participants came up in response to the on-going informal conversations among project researchers and study participants about the medical dispute over whether more or fewer heart-healthy people should be taking cholesterol-lowering drugs. This, quite polarized, scientific disagreement means that many users of the medication are uncertain about whether to take it or not. Since the uncertain effects of cholesterol-lowering statins often came up in conversations in the project researchers found themselves reflecting on the project's position in the debate about the effect of treatment. Project researchers had different takes on what they, as experts, should respond when study participants asked. Bruun had encountered this same doubt about what it would be best to say in her interviews with study participants. Coming across this both pragmatic and deeply ethical question among both researchers and subjects led to the idea of organizing a meeting between study participants and researchers in the LIFESTAT project.

The idea was welcomed in the project steering committee meeting where Bruun and her anthropology and public health colleagues presented the proposal. After the meeting, one of the doctors, however, hesitantly expressed doubts about the purpose of "inviting participants in" in this way. What could come out of such a meeting and what it would contribute to? Bruun and her colleague made it clear to project colleagues that the intention was to both share research insights with study participants and to examine how the debate between researchers and participants would take shape. The research participant meeting would produce data for all involved parties at the same time, since all involved parties would be research objects in the context of the meeting.

During the meeting, researchers from five different disciplines, incl. anthropology, presented the preliminary results of their research. All presentations concluded with more or less the same observation that no definite answer could be offered in response to the question that most of the participants were preoccupied with: whether they should continue to take their statins or not. Whereas many of the presenting researchers found this lack of an answer unsatisfactory, most participants remained surprisingly resigned to the fact that they would have to continue deciding for themselves what to do.

A subsequent evaluation of the meeting found that most participants and researchers had found the meeting very fruitful, which was quite surprising. First, because volunteers and researchers shared their doubts about the solution to high cholesterol levels. There were different views of the basis for statins having become such a widespread preventive treatment, and the juxtaposition of these views destabilized 
our knowledge. We were all in doubt, both experts and users. Secondly, because users seemed to accept that even the experts could not give exact answers. This acceptance is at odds with the third and final aspect here: the meeting not only comprised scholars with different ways of seeing the problem of high cholesterol, but also users who came to the meeting in the hope of gaining new insight.

The meeting turned into a space for the sharing of doubts. Simultaneously, it created resignation and opportunity for critically assessing the treatment practice that apply today. As a result of the meeting, an interdisciplinary group of researchers in the project are now focusing on a new object, i.e. the resigned acceptance that characterizes many participants vis-à-vis their responsibility to make their own decisions regarding their treatment. By establishing a patient panel, the LIFESTAT project has followed up on this sense of resignation by developing a tool for dialogue between patients and doctors when they discuss statin therapy. The dialogue tool will not provide answers that traditional risk assessment tools based on epidemiological data do, but lead patients and doctors through a shared reflection that can end in several possible treatment decisions.

Both meetings turned away from a one-dimensional approach to the question of responsibility for one's own health. As such it makes sense to say that, for a moment at least, the causalities between the problems and their solutions were suspended. It was not possible to assign the right to define who should frame a problem and thus a spontaneous democratic situation emerged, in which none of the participants were convinced that they could provide a solution. The consequences were felt as affective states of doubt and awkwardness, rather than as new arguments. The focus was thus turned away from an implicit expectation that all project colleagues and meeting participants were interested in the same solution, and turned instead to a shared analysis of what the problem could possibly be. The affective tensions in these situations, we suggest, can be characterized as enacting a'response-ability' that allow for a significant moment of sharing difference.
In this regard, Verrans concept of 'generative critique' is useful to point to the ways that doubt and awkwardness could be productive or have effects. Generative critique is a practical potential. To be generatively critical is to make connections and to engage each other and the world. Verran (2001) points out that it takes practice to see the relationship between differences without necessarily implying that they can be compared. This is what Verran elsewhere describes as "the complex politics of 'doing difference together"' (Verran, 2011:422). In the concrete collaborations discussed in this article, these connections came to the fore through sensitivity to difference as new questions and responsibilities arising out of the collaboration: What and how could one advise people to choose with regard to statin use and how to connect obesity and health?

\section{Discussion: Generative response and participation in interdisciplinary collaboration}

Interdisciplinary collaboration sets a specific framework for professional commitment through the meetings and the connections created between differences in practice. For many years, analyses of interdisciplinary research have shown how such differences could be contained within boundary objects that allowed researchers from different disciplines and other involved parties to continue pursuing their own disparate interests, largely unaffected by the participation of others. Based on our experience in two interdisciplinary research projects we have tried to examine what exactly goes on in day-to-day interdisciplinary research collaboration. We have taken note of the way difference often registers as affective tensions in various meetings, which carry with them a potentiality of signposting when one idea becomes consequential for another. We have tried to show how interdisciplinary engagement can open for new forms of response and participation through attention to the affective tensions that may signpost meetings between differences and the forging of other or new connections between people and problems.

We have also argued that the potential of interdisciplinary research, which has been celebrated 
as a robust solution, perhaps lie in the deliberate exploration of contested grounds, i.e. in identifying and defining what action should be taken. In this process, interdisciplinary collaboration has the potential to become a more reflexive mode of knowledge production.

The situations analysed here show how collaborators' ways of approaching and relating to each other and at the same time constituting the shared project is not something that happened by itself. Making connections between differences involves more than disciplinary expertise, and more than the sociality of meeting others in a joint project. Staying in the encounters where disconcerting moments allow new knowledge to unfold benefits from attention to affect.

We think of affect in knowledge production as a marker of an on-going, but not necessarily explicit process of re-connecting and re-negotiation of problems, aims and expectations. This work, which we might think of as interdisciplinary expertise, is rarely reported in the overall reports of interdisciplinary projects, but it has the potential, in terms of the meeting of ideas that this work sets in motion, to advance agendas in a subtle and also more fundamental way than what we typically see in interdisciplinary research projects.

Our shared experience of meeting difference and becoming "response-able" of more or less explicitly addressed connections between such differences may be seen as one among several possible effects of interdisciplinary collaboration and as a generative response that can indicate how a problem may be examined in ways that destabilize politically strategic agendas, expertise, and evidence hierarchies. By applying the concept of 'response-ability' we have analysed the work of affect in collaboration and unfolded the knowledge production inherent in the concrete processes of doing connections between disciplines, people and problems, and hence interdisciplinary projects' potential for social change.

\section{Acknowledgements}

This article is based on ethnographic fieldwork that was made possible by funds from the University of Copenhagen's Excellence Programme for Interdisciplinary Research. We are most grateful for the financial support that made this work possible.

We especially want to thank our project colleagues across disciplines for discussions and curiosity. We would also like to thank the anonymous reviewers for critically engaging with our work. 


\section{References}

Albert M, Laberge S and Hodges BD (2009) Boundary-work in the health research field: Biomedical and clinician scientists' perceptions of social science research. Minerva 47: 171-194.

Albert M, Laberge S, Hodges BD, Regehr G and Lingard L (2008) Biomedical scientists' perceptions of the social sciences in health research. Social Science and Medicine 66: 2520-2531.

Balmer AS, Calvert J, Marris C, et al. (2015) Taking Roles in Interdisciplinary Collaborations: Reflections on Working in Post-ELSI Spaces in the UK Synthetic Biology Community. Science and Technology Studies 28(3): 3-25.

Balmer AS, Calvert J, Marris C, et al. (2016) Five rules of thumb for post-ELSI interdisciplinary collaborations. Journal of Responsible Innovation 3(1): 73-80.

Barry A and Born G (2013) Interdisciplinarity: Reconfigurations of the Social and Natural Sciences. London: Routledge.

Bennett J (2009) Vibrant Matter: A Political Ecology of Things. Durham, NC: Duke University Press.

Blackman L and Venn C (2010) Affect. Body \& Society 16(1): 7-28. https://doi.org/10.1177/1357034X09354769

Callard F and Fitzgerald D (2015) Rethinking interdisciplinarity across the Social Sciences and Neurosciences. London: Palgrave Macmillan.

Christensen, CL, Wulff HJ, Krasnik A, et al. (2016) LIFESTAT - Living with statins: An interdisciplinary project on the use of statins as a cholesterol-lowering treatment and for cardiovascular risk reduction. Scandinavian Journal of Public Health 44, 534-539.

Elgaard Jensen T (2012) Intervention by Invitation: New Concerns and New Versions of the User in STS. Science Studies 25(1): 13-36.

Fitzgerald D, Littlefield MM, Knudsen KJ, Tonks J and Dietz MJ (2014) Ambivalence, equivocation and the politics of experimental knowledge: A transdisciplinary neuroscience encounter. Social Studies of Science 44(5): 701-721.

Frodeman R, Klein JT, and Mitcham C (2010) The Oxford handbook of interdisciplinarity. Oxford: Oxford University Press.

Gibbons M, Limoges C, Nowotny H, et al. (1994) The New Production of Knowledge: The Dynamics of Science and Research in Contemporary Societies. London: Sage Publishing.

Gregg M and Seigworth GJ (2010) The Affect Theory Reader, North Carolina: Duke University Press.

Hammersley M and Atkinson P (1995) Ethnography: Principles in Practice (second edition). London: Routledge. Haraway D (1997) Modest Witness@Second Millennium. FemaleMan Meets OncoMouseTM. London: Routledge.

Hastrup F (2014) Analogue Analysis. Ethnography as Inventive Conversation. Ethnologia Europaea. Journal of European Ethnology 44(2): 48-60.

Hillersdal L, Christensen BJ and Holm L (2016) Changing tastes: learning hunger and fullness after weightloss surgery. Sociology of Health and IIIness 39(3):474-487 DOI: 10.1111/1467-9566.12504

Hillersdal L, Christensen BJ and Holm L (2015) Patients' strategies for eating after Gastric Bypass Surgery: a qualitative study. European Journal of Clinical Nutrition, 70: 523-527. DOI: 10.1038/ejcn.2015.212

Jasanoff S (2004) States of knowledge. The Co-production of Science and Social Order. London and New York: Routledge.

Jerak-Zuiderent S (2015) Keeping open by re-imagining laughter and fear. The Sociological Review 63: 897-921. doi:10.1111/1467-954X.12221 
Jespersen AP, MK Petersen, C Ren and M Sandberg (2012) Introduction: Cultural Analysis as Intervention. Science Studies 25(1): 3 - 12.

Jespersen AP, Bønnelycke J and Eriksen HH (2013) Careful Science? Bodywork and Care Practices in Randomised Clinical Trials. Sociology of Health and IIIness 35(8):655 - 669.

Kerr A and Garforth L (2016) Affective practices, care and bioscience: a study of two laboratories. The Sociological Review (64): 3-20.

Klein JT (2010) A taxonomy of Interdisciplinarity. In: Frodeman R, Klein JT and Roberto Pacheco RCS (eds): The Oxford Handbook of Interdisciplinarity, 2nd Edition. Oxford Handbooks. City: Publisher, pp. 15-30.

Larsen MR, Petersen MB, Gram AS, et al. (2017) The GO-ACTIWE randomized controlled trial - An interdisciplinary study designed to investigate the health effects of active commuting and leisure time physical activity. Contemporary Clinical Trials 53(2): 122-129

Lindvig K and Hillersdal L (2018) Strategically unclear? Exploring an excellence programme for interdisciplinary research, (published on-line ahead of print).

Lupton D (1995) The Imperative of Health. Public Health and the Regulated Body. London: Sage Publications Ltd.

Marres N (2009) Testing powers of engagement. Green living experiments, the ontological turn and the undoability of involvement. European Journal of Social Theory 12(1): 117-133.

Marcus GE (1995) Ethnography in/of the world system: The emergence of Multi-sited Ethnography. Annual Review of Anthropology 24: 95-117.

Meloni M (2014) How biology became social, and what it means for social theory. The Sociological Review 62(3): 593-614.

Moran J (2010) Interdisciplinarity (2.). London: Routledge.

Morris N and Hebden JC (2008) Evolving Collaborations: A self-referential case-study of a social/natural sciences collaborative project. Science Studies (21):27-46

Myers N (2006) Animating Mechanism: Animations and the Propagation of Affect in the Lively Arts of Protein Modelling. Science \& Technology Studies 19(2): 6-30.

Myers N (2008) Embodiments and the Body-work of Modeling in Protein Crystallography. Social Studies of Science 38(2): 163-199.

Nowotny H, Scott P and Gibbons M (2001) Re-thinking Science. Knowledge and the Public in an Age of Uncertainty. Cambridge: Polity.

Parker JN and Hackett EJ (2012) Hot spots and hot moments in scientific collaborations and social movements. American Sociological Review 77(1): 21-44.

Pedersen DB, Stjernfelt F and Køppe S (2015) Kampen om disciplinerne: Viden og videnskabelighed i humanistisk forskning. København: Hans Reitzel.

Prainsack B, Svendsen MN, Kock L and Ehrich K (2010) How do we collaborate? Social science researchers' experience of interdisciplinarity in biomedical settings. BioSocieties 5: 278-286.

Rabinow P and Bennett G (2012) Designing Human Practices: An Experiment with Synthetic Biology. Chicago, IL:The University of Chicago Press.

Repko AF and Szostak R (2017) Interdisciplinary research process and theory. Los Angeles: SAGE.

Rip A (2009) Futures of ELSA (Science and society series on convergence research). EMBO Reports 10: 666-670

Rose N (2013) The Human Sciences in a Biological Age. Theory, Culture \& Society 30(1): 3-34. 
Seyfert R (2012) Beyond Personal Feelings and Collective Emotions: Toward a Theory of Social Affect. Theory, Culture \& Society 29(6): 27-46.

Star SL and Griesemer JR (1989) Institutional ecology, 'translations' and boundary objects: Amateurs and professionals in Berkeley's Museum of Vertebrate Zoology, 1907-39. Social Studies of Science 19(3): 387-420.

Strathern M (2004) Commons and Borderlands: Working Papers on interdisciplinarity, Accountability and the Flow of Knowledge. Oxford: Sean Kingston Publishing.

Suchman L (2013) Consuming Anthropology. In: Barry A and Born G (eds) Interdisciplinarity: reconfigurations of the social and natural sciences. London: Routledge, pp. 141-160.

Verran H (1999) Staying true to the laughter in Nigerian classrooms. The Sociological Review 47: $136-156$.

Verran H (2001) Science and an African Logic. Chicago: University of Chicago Press.

Verran H (2011) Imagining nature politics in the era of Australia's emerging market in environmental services interventions. The Sociological Review, 59(3): 411-431.

University of Copenhagen (2012). UCPH 2016-Funds Call, June 20th. University of Copenhagen.

Zierhofer W and Burger P (2007) Disentangling Transdisciplinarity: An Analysis of Knowledge Integration in Problem-Oriented Research. Science Studies 20(1): 51-74. 


\section{Notes}

1. https://innovayt.eu/horizon-2020/

2. See www.go.ku.dk

3. See www.lifestat.ku.dk

4. Many forms and degrees of collaboration between disciplines are described with the terms inter-, trans-, multi-, etc. in the literature classifying how disciplines may work together (Klein, 2010, Barry and Born, 2013). We are not so concerned with particular definitions of cross-scientific forms, but we use the concept interdisciplinarity as a common term for collaboration with other disciplines. Our examples relate specifically to cooperation across the natural and social sciences.

5. Accepting the premise and concept of obesity did not imply that those among us not being biomedical researchers in the project accepted the biomedical term of obesity as the right characterisation of the problem. Instead, one of the research objectives was to ethnographically follow the configuration of 'the obesity problem' among diverse groups of mainly biomedical researchers. Furthermore, the sharing of different conceptualizations and articulations was central in concrete project meetings, and particularly in the dialogic experiment on appetite analysed here.

6. The ethnographic studies that we report from were approved as part of the larger research projects by the local ethics committee, Frederiksberg, Copenhagen and the Danish Data Protection Agency. All materials and narratives were anonymized before sharing. Besides, we have continuously presented findings and conclusions from our work and have been able to discuss it with our project colleagues.

7. Thanks to Jonas Winther, ethnologist and doctoral student in the GO project, for contributing to the development and testing of this concept. 